Article

\title{
Synergy of Cobalt and Silver Microparticles Electrodeposited on Glassy Carbon for the Electrocatalysis of the Oxygen Reduction Reaction: An Electrochemical Investigation
}

\section{Claudio Zafferoni ${ }^{1, *}$, Giacomo Cioncoloni ${ }^{2}$, Maria Luisa Foresti ${ }^{1}$, Luigi Dei ${ }^{1}$, Emiliano Carretti ${ }^{1}$, Francesco Vizza ${ }^{3}$, Alessandro Lavacchi ${ }^{3}$ and Massimo Innocenti ${ }^{1, *}$}

1 Department of Chemistry, University of Florence, via della Lastruccia 3, 50019 Sesto Fiorentino (Fi), Italy; E-Mails: marialuisa.foresti@unifi.it (M.L.F.); luigi.dei@unifi.it (L.D.); carretti@csgi.unifi.it (E.C.)

2 WestCHEM, School of Chemistry, University of Glasgow, University Avenue, G12 8QQ Glasgow, UK; E-Mail: g.cioncoloni.1@research.gla.ac.uk

3 Institute of Chemistry of OrganoMetallic Compounds, ICCOM-CNR, via Madonna del Piano 10, 50019 Sesto Fiorentino (Fi), Italy; E-Mails: francesco.vizza@iccom.cnr.it (F.V.); alessandro.lavacchi@iccom.cnr.it (A.L.)

* Authors to whom correspondence should be addressed; E-Mails: claudio.zafferoni@unifi.it (C.Z.); m.innocenti@unifi.it (M.I.); Tel.: +39-055-457-3097 (C.Z).

Academic Editor: Nicola Cioffi

Received: 8 May 2015 / Accepted: 4 August 2015 / Published: 7 August 2015

\begin{abstract}
The combination of two different metals, each of them acting on different steps of the oxygen reduction reaction (ORR), yields synergic catalytic effects. In this respect, the electrocatalytic effect of silver is enhanced by the addition of cobalt, which is able to break the $\mathrm{O}-\mathrm{O}$ bond of molecular oxygen, thus accelerating the first step of the reduction mechanism. At the same time, research is to further reduce the catalyst's cost, reducing the amount of Ag, which, even though being much less expensive than Pt, is still a noble metal. From this point of view, using a small amount of Ag together with an inexpensive material, such as graphite, represents a good compromise. The aim of this work was to verify if the synergic effects are still operating when very small amounts of cobalt $\left(2-10 \mu \mathrm{g} \cdot \mathrm{cm}^{-2}\right)$ are added to the microparticles of silver electrodeposited on glassy carbon, described in a preceding paper from us. To better stress the different behaviour observed when cobalt and silver are contemporarily present in the deposit, the catalytic properties of cobalt alone were
\end{abstract}


investigated. The analysis was completed by the Levich plots to evaluate the number of electrons involved and by Tafel plots to show the effects on the reaction mechanism.

Keywords: ORR; electrodeposition; silver; cobalt

\section{Introduction}

The catalytic properties of silver were reported long ago [1-6]. More recently, silver single crystals were used to stress the surface sensitivity of ORR and the $\mathrm{pH}$ effect $[7,8]$. The most appropriate reaction scheme for the ORR provides two different four-electron pathways [7-13], the first one directly leading to the formation of $\mathrm{H}_{2} \mathrm{O}$ and the second one occurring with an intermediate two-electron step with the formation of $\mathrm{H}_{2} \mathrm{O}_{2}$, part of which is subsequently reduced to $\mathrm{H}_{2} \mathrm{O}$ in a further two-electron step. It must be stressed that the possible formation of $\mathrm{H}_{2} \mathrm{O}_{2}$ must be minimized, both for the lower energy involved (two electrons in place of four) and for the dangerous aggressive effect on the membrane used in fuel cells. The direct four-electron reaction with a very small $(0.5 \%-2.5 \%)$ peroxide formation occurs in the entire potential range in $0.1 \mathrm{M} \mathrm{KOH}$, but only at the highest overpotentials in $0.1 \mathrm{M} \mathrm{HClO}_{4}$, suggesting a useful utilization of silver in alkaline media. This result has been very recently supported by the surface Pourbaix diagram of the $\operatorname{Ag}(111)$ obtained by density functional theory calculations [14].

To completely remove $\mathrm{Pt}$ and to replace it with less expensive materials, bimetallic electrocatalysts have been proposed to exploit a synergic mechanism with one metal able to break the $\mathrm{O}-\mathrm{O}$ bond of molecular oxygen and the second metal effective in reducing the adsorbed oxygen thus formed [15-18]. The theoretical assumptions have been supported by the experimental evidence of the catalytic activity of Ag-Co mixtures [15,17,18].

Silver substrates can be electrochemically modified at the nanometric scale through electrodeposition of metals able to exert catalytic synergic effects $(\mathrm{Co}, \mathrm{Ni}, \mathrm{Fe})$ or chalcogenide nanofilms. The synergic effect of $\mathrm{Ag}-\mathrm{Co}$ has been verified by electrodepositing Co on $\mathrm{Ag}(111)$ surfaces so as to form nanometric islands using a template-assisted procedure [18]. In particular, the maximum synergic effect was found to be exerted by a Co amount equal to $30 \%$ of $\mathrm{Ag}$, in good agreement with the theoretical previsions $[15,16]$. Later, a monolayer of $\mathrm{Co}$, or $\mathrm{Fe}$, or $\mathrm{Co}-\mathrm{Fe}$ mixtures was deposited through electrodesorption-based atomic layer deposition (SEBALD) [19], and their catalytic effects, even though small, were verified [20].

Currently, the research is directed toward further reducing the catalysts' cost by reducing the amount of Ag, which, even being much less expensive than Pt, still is a noble metal. From this point of view, using a small amount of $\mathrm{Ag}$, Au or Pd together with an inexpensive material, such as graphite, represents a good compromise [21-25]. Electrocatalysts are deposited by more or less complex chemical procedures or by gas phase methods, and only a few references cite electrodeposition [26]. However, electrodeposition represents a good method to limit the amount of depositing metals through the Faraday laws and, actually, allows the formation of thin and homogeneous Ag deposits [27-30]. With electrodeposition, the morphology and structure of deposits can be changed by simply varying the experimental parameters, such as electrolyte composition, temperature, solutions, $\mathrm{pH}$ and the electric variables (either current or potential), while working at ambient temperature and pressure, thus only requiring inexpensive experimental equipment. On this basis, [31] reports the electrocatalytic properties 
of Ag microparticles electrodeposited on glassy carbon (GC), which, itself, promotes the two-electron pathway leading to the formation of $\mathrm{H}_{2} \mathrm{O}_{2}$ [6].

An electrochemical quartz crystal microbalance investigation has recently shown the formation of cobalt hydroxide simultaneously with cobalt deposition due to the $\mathrm{pH}$ variation near the surface electrode caused by the parallel hydrogen evolution reaction [32]. In the alkaline electrolytes and in the potential range used to study ORR by means of the rotating disk electrodes, the deposits of Co are significantly oxidized to $\mathrm{Co}(\mathrm{OH})_{2}$ [33,34]. For its part, cobalt hydroxide, while promoting the two-electron pathway in ORR, also shows an autocatalytic mechanism with an intermediate step, where oxygen is again formed [35-37].

In the present paper, we verified the possibility of combining the results of [28] and [38], which is to investigate if the electrocatalytic effect of $\mathrm{Ag}$ particles could be further increased by adding a controlled amount of Co.

\section{Results and Discussion}

\subsection{Electrodeposition of Increasing Amounts of Cobalt on GC and Their Effect on ORR}

Figure 1 shows the cyclic voltammogram of Co on the GC electrode between 0.2 and $-1.0 \mathrm{~V}$.

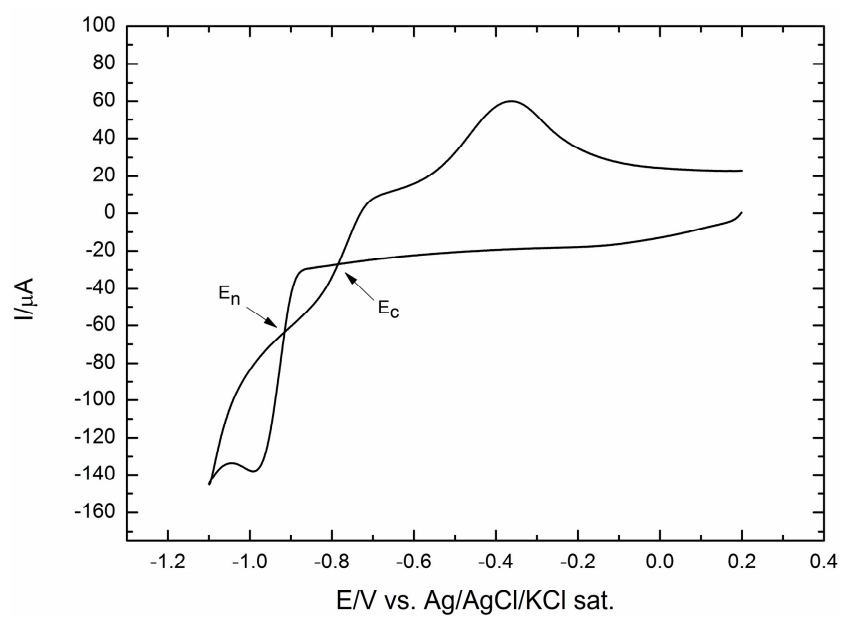

Figure 1. Linear sweep voltammograms for Co deposition from $\mathrm{Co}(\mathrm{II})\left(5 \times 10^{-3} \mathrm{M}\right)$ solution in ammonia buffer from $0.2 \mathrm{~V}--1.1 \mathrm{~V}$. The scan rate is $50 \mathrm{mV} \cdot \mathrm{s}^{-1}$.

During the forward scan, the cathodic current increases sharply once nucleation starts to occur, since it is related to the increase of the density of the nuclei and the crystal growth [38,39]. During the reverse scan, two crossovers between the cathodic branches' current are observed. The more negative crossover corresponds to the nucleation overpotential, $E_{n}$, whereas the less negative one is the overcrossing potential, $E_{c}$. In the potential range between $E_{n}$ and $E_{c}$, the cathodic current recorded in the reverse scan is greater than that recorded in the forward one. As reported in [38], this higher cathodic current suggests that the energy required for cobalt deposition on the cobalt film (formed during the forward scan) is lower than that required for cobalt deposition on the bare $\mathrm{GC}$ electrode.

Increasing amounts of Co were deposited at a potential, $\mathrm{E}=-0.93 \mathrm{~V}$, just a bit negative to $\mathrm{E}_{\mathrm{n}}$. As for the Ag deposition reported in [31], a purpose-developed program allowed for strictly controlling the 
extent of deposition. The charge involved in Co(II) reduction was continuously monitored, and as soon as it reached the wanted charge value, the cobalt solution was suddenly replaced by ammonia buffer. However, unlike silver, the electrochemical check of cobalt deposition performed by anodic stripping was distorted by the chemical formation of the solid $\mathrm{Co}(\mathrm{OH})_{2}$ on the electrode surface. As an example, Figure 2 shows that only a very small charge, about $2 \mathrm{mC}$, was involved in the electrochemical reoxidation of a Co deposit corresponding to $24 \mathrm{mC}$. However, energy dispersive $\mathrm{x}$-ray spectroscopy (EDX) confirms the presence of cobalt in our samples.

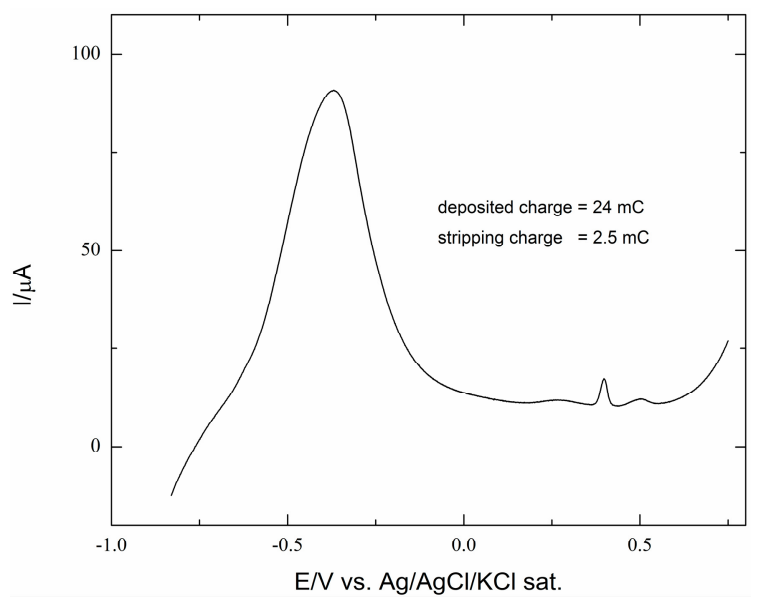

Figure 2. Stripping voltammetry of a Co deposit of $24 \mathrm{mC}$ (equal to $9.3 \mu \mathrm{g} \cdot \mathrm{cm}^{-2}$ ) as recorded by scanning the potential from $-0.8-+0.8 \mathrm{~V}$ at a scan rate of $10 \mathrm{mV} \mathrm{s}^{-1}$. The small peak at $+0.4 \mathrm{~V}$ can be associated with the formation of $\mathrm{Co}(\mathrm{III})$.

Incidentally, the current involved in all Co depositions decreases slowly up to a deposited charge of $3.5 \mathrm{mC}$, and then, it turns to increase constantly, even though slowly, thus suggesting that from that point forward, the deposition occurs on already formed nuclei, rather than on the GC surface. The catalytic effects on ORR of the various deposits of cobalt reported in Table 1 were then analysed. Figure 3 shows the polarization curves (positive sweep direction at $500 \mathrm{rpm}$ ) as recorded on a rotating-disc working electrode for the ORR on the various deposits of cobalt reported in Table 1. The figure shows that the onset potential progressively shifts towards less negative potentials up to a deposit equal to $18 \mathrm{mC}$, and then, it progressively shifts back to the negative potentials for the largest Co deposits.

At the same time, the limited cathodic currents follow a similar behaviour. This is well depicted by both the plots of the potentials at which the curves reach the value of $0.5 \mathrm{~mA} \cdot \mathrm{cm}^{-2}$ and the currents recorded at a potential $\mathrm{E}=-1.0 \mathrm{~V}$. The result is the volcano curves reported in Figure 4 that are typical of a mechanism where the adsorbed step is the rate-determining step.

Table 1. The deposited charges of cobalt and the corresponding amount expressed in $\mu \mathrm{g} \mathrm{cm}^{-2}$.

\begin{tabular}{cc}
\hline Programmed Charge/mC & Co Loading/ $\mathbf{\mu g} \mathbf{~ c m}^{-\mathbf{2}}$ \\
\hline 6 & 2.3 \\
12 & 4.7 \\
18 & 7.0 \\
24 & 9.3 \\
36 & 14.0 \\
\hline
\end{tabular}




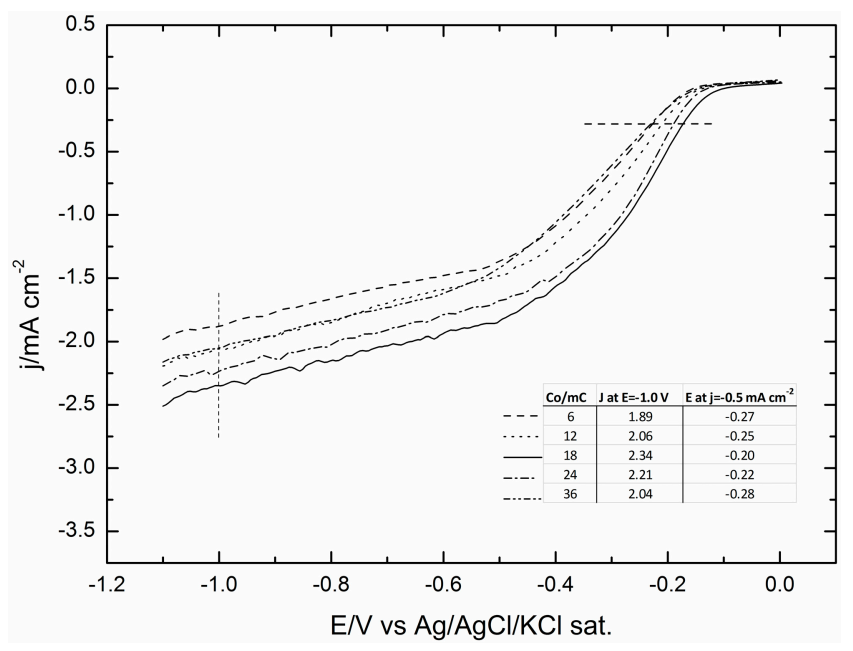

Figure 3. Oxygen reduction reaction (ORR) in $\mathrm{KOH} 0.1 \mathrm{M}$ on glassy carbon $(\mathrm{GC})$ covered by increasing amounts of Co from $6 \mathrm{mC}-36 \mathrm{mC}$ recorded at $500 \mathrm{rpm}$ and with a scan rate of $50 \mathrm{mV} \cdot \mathrm{s}^{-1}$.
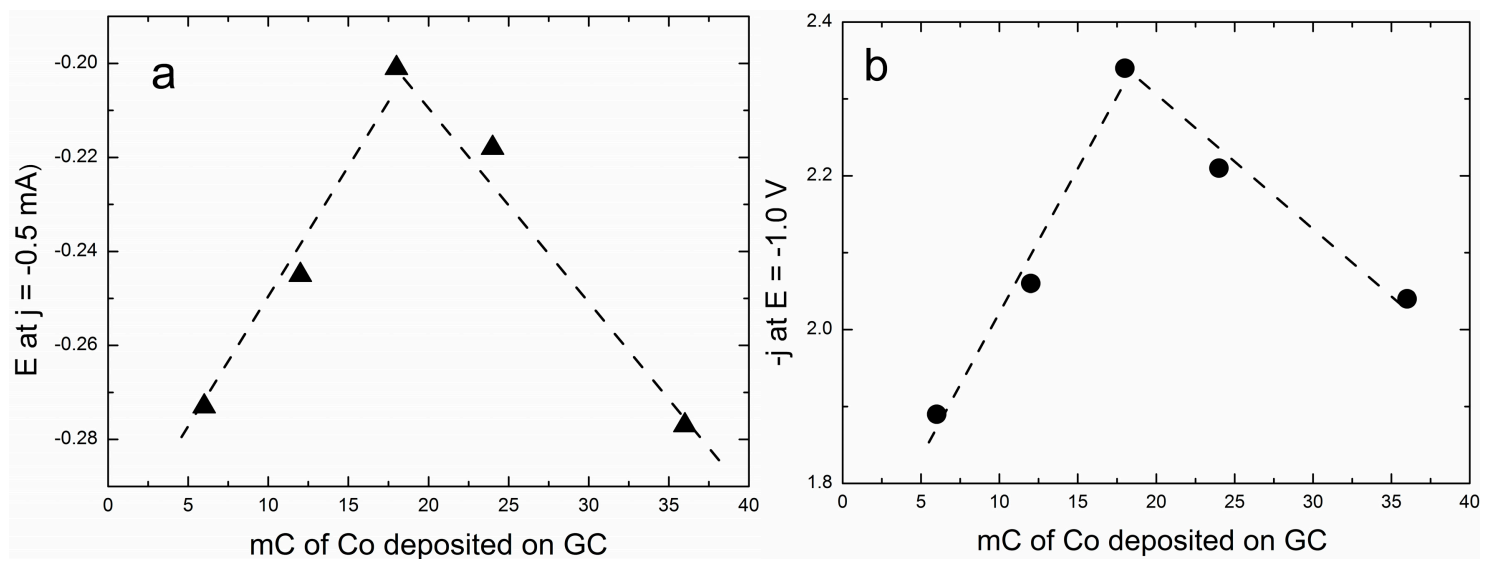

Figure 4. (a) Volcano curve as obtained by plotting the potential values at $\mathrm{j}=-0.5 \mathrm{~mA} \cdot \mathrm{cm}^{-2}$, and (b) the current density values at $\mathrm{E}=-1.0 \mathrm{~V}$ versus the charge associated with the Co deposits on GC.

Here, the adsorbed species is superoxide ion on $\mathrm{Co}(\mathrm{OH})_{2}$, and therefore, the increasing catalytic effect on the left branch of the volcano curve could just be explained by the increased surface of the cobalt deposits. On the other hand, the decrease of the cobalt surface along the right branch could hardly be explained other than with the increased coverage of superoxide occurring in the left branch.

According to [35], the mechanism of ORR on $\mathrm{Co}(\mathrm{OH})_{2}$ provides the first $\mathrm{pH}$-independent step:

$$
\mathrm{O}_{2}+\mathrm{e}^{-} \rightarrow \mathrm{O}_{2}^{-}
$$

followed by the disproportionation reaction (2) or the electrochemical step (3):

$$
\begin{gathered}
2 \mathrm{O}_{2}^{--}+\mathrm{H}_{2} \mathrm{O} \rightarrow \mathrm{HO}_{2}^{-}+\mathrm{O}_{2}+\mathrm{OH}^{-} \\
\mathrm{O}_{2}^{-}+\mathrm{H}_{2} \mathrm{O}+\mathrm{e}^{-} \rightarrow \mathrm{HO}_{2}^{-}+\mathrm{OH}^{-}
\end{gathered}
$$

In its turn, $\mathrm{HO}_{2}^{-}$formed in Step (3) may still produce $\mathrm{O}_{2}$ in Step (4):

$$
2 \mathrm{HO}_{2}^{-} \rightarrow 2 \mathrm{OH}^{-}+\mathrm{O}_{2}
$$


Reaction (1) is responsible for the first reduction peak at about $-0.4 \mathrm{~V}$ that is observed both at the GC and at $\mathrm{GC} / \mathrm{Co}(\mathrm{OH})_{2}$ stationary electrodes. However, the comparison of the cyclic voltammograms reported in Figure 5a shows that the presence of cobalt hydroxide imparts a high catalytic effect due to re-reduction of $\mathrm{O}_{2}$ replenished from Reaction (2) and/or (4). Then, a second ill-defined reduction peak due to the concomitant side two-electron reduction of Step (5) takes place at more negative potentials (at about $-0.9 \mathrm{~V})$ :

$$
\mathrm{O}_{2}+\mathrm{H}_{2} \mathrm{O}+2 \mathrm{e}^{-} \rightarrow \mathrm{HO}_{2}^{-}+\mathrm{OH}^{-}
$$

Cyclic voltammograms recorded at different scan rates, $v$, at the $\mathrm{GC} / \mathrm{Co}(\mathrm{OH})_{2}$ electrode allow one to verify that $\mathrm{i}_{\mathrm{p}} / \mathrm{v}$ decreases with $\mathrm{v}$, thus confirming the autocatalytic mechanism imparted by the presence of cobalt (Figure $5 b$ ).
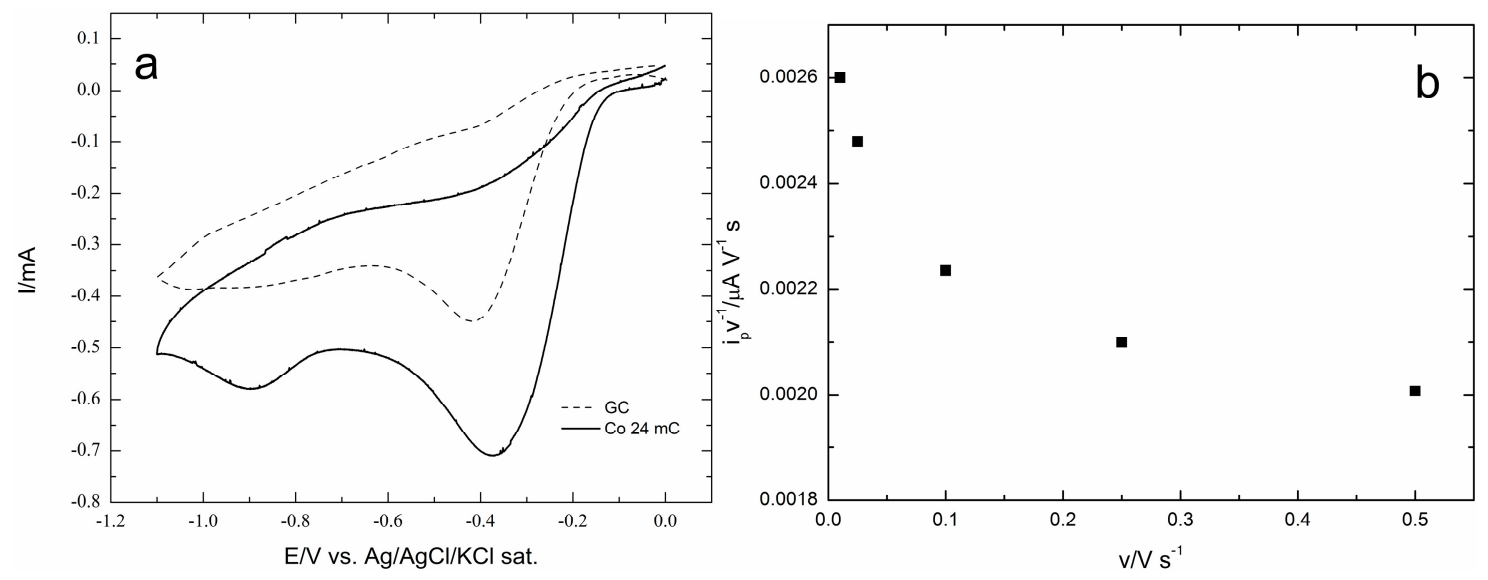

Figure 5. (a) Cyclic voltammograms recorded at $\mathrm{GC}$ (dashed curve) and at $\mathrm{GC} / \mathrm{Co}(\mathrm{OH})_{2}$ (solid lines) stationary electrodes; (b) $\mathrm{i}_{\mathrm{p}} / \mathrm{v}$ ratio as a function of the scan rate $\mathrm{v}$.

\subsection{Electrodeposition of Increasing Amounts of Cobalt on GC Covered by Silver Microparticles}

To verify the existence of a synergic effect of Co on the silver microparticles of [31], amounts of Co similar to those used in the preceding paragraph were added to the silver deposit of $12 \mathrm{mC}$ (corresponding to $17.1 \mu \mathrm{g} \cdot \mathrm{cm}^{-2}$ ) that had given the best catalytic effect. In the first series of measurements, we left out the activation treatment on silver microparticles that had conferred enhanced catalytic effects to the silver microparticles. This allowed investigating if the synergic effect of Co on silver, already reported in [18], still worked if silver were in the form of microparticles.

Figure 6 shows that the electrodeposition of $\mathrm{Co}$ on a GC substrate already covered by $\mathrm{Ag}$ microparticles is almost different from that on the bare GC electrode. In fact, there are no more intersection points, and the onset of the cathodic peak shifted to less negative potentials. It must be noted that the presence of an overcrossing potential $E_{n}$ is a major parameter in the classification of the characteristics of the nucleation growth mechanism [39]. Therefore, the absence of such an overcrossing potential may tentatively suggest that Co deposition takes place apparently without creating new nuclei.

Figure 7 shows the polarization curves (positive sweep direction at $500 \mathrm{rpm}$ ) as recorded on a rotating-disc working electrode for the ORR on the above deposits of cobalt together with the curve of the only deposit of $12 \mathrm{mC}$ of $\mathrm{Ag}$. 


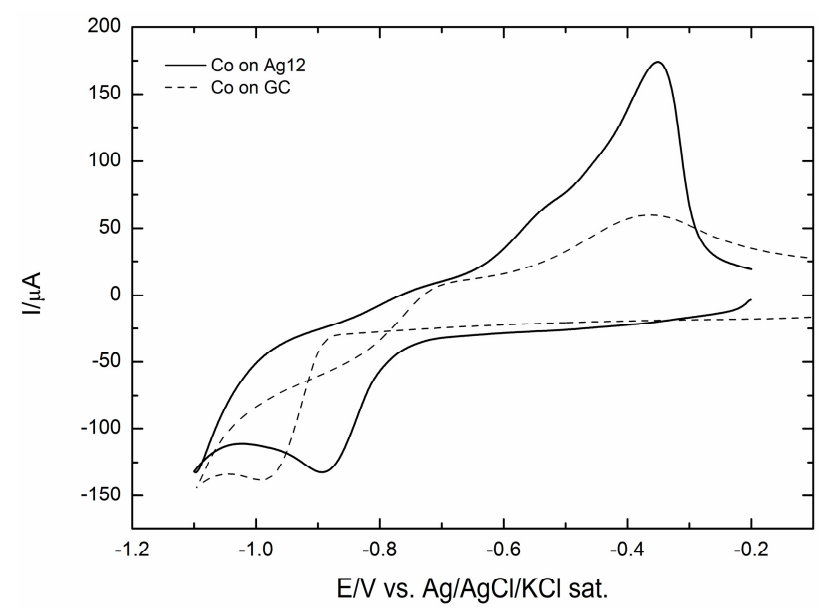

Figure 6. Cyclic voltammograms of $\mathrm{Co}(\mathrm{II})$ solution $\left(5 \times 10^{-3} \mathrm{M}\right)$ recorded at the $\mathrm{GC}$ electrode (dashed curve) and at the GC/Ag12 mC electrode (solid line).

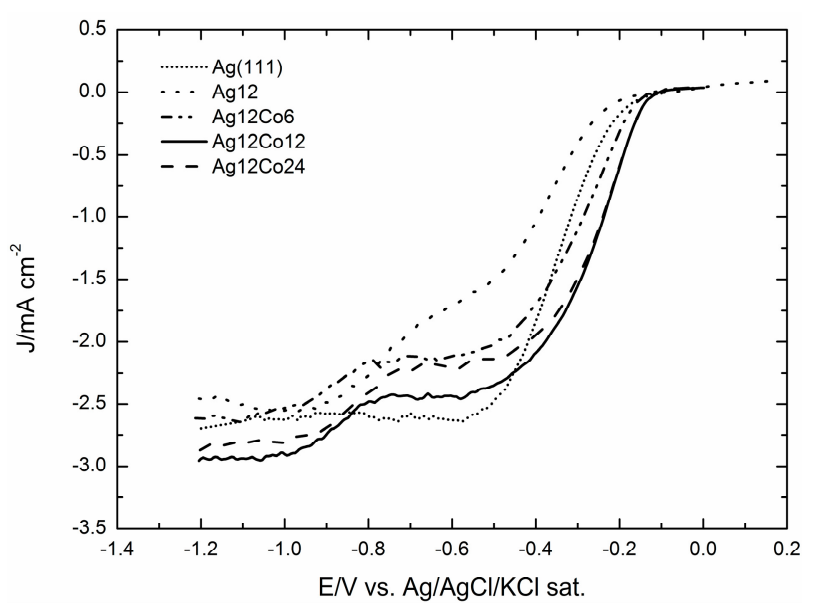

Figure 7. Comparison between the oxygen reduction reaction (ORR) on the $\mathrm{Ag}(111)$ electrode and on the GC/Ag12 electrode [31] and the GC electrode covered by an increasing amount of Co recorded at $500 \mathrm{rpm}$ and with a scan rate of $50 \mathrm{mV} \cdot \mathrm{s}^{-1}$.

Figure 7 shows that the addition of Co enhances the catalytic effect on ORR, even with respect to $\mathrm{Ag}(111)$, and that the maximum effect is shown by the addition of $12 \mathrm{mC}$ of Co. A still more interesting comparison is that offered by Figure 8a-c, where the ORR curves obtained on Ag are reported together with those recorded after the addition of 6,12 or $24 \mathrm{mC}$ of Co and together with the same amounts of Co, but without Ag. These figures show that in all cases, the ORR recorded on Co alone starts before that recorded on Ag, probably because at the very beginning of the reduction curve, the autocatalytic mechanism prevails. However, going on towards the negative values, the current involved is lower than on $\mathrm{Ag}$ alone, because of the higher catalytic effect of silver. In all cases, the contemporary presence of Co and Ag gets the best of both, so that not only the ORR is anticipated, but also the limiting cathodic current increases, thus indicating a higher number of electrons involved.

Actually, as reported in [31], the catalytic effect of the silver microparticles deposited on GC substantially improves with an activation protocol based on pretreatment oxidation/reduction cycles. We tentatively attributed the enhancement of the catalytic effect to the formation of $\mathrm{Ag}-\mathrm{OH}$, which is assumed to be active towards ORR catalysis [21]. Therefore, we applied the same activation protocol to 
the deposits containing both silver and cobalt, and of course, we compared the ORR curves with that of the activated microparticles of silver alone reported in [31]. Figure 9 shows that the addition of Co still enhances the catalytic effect and that the best curve is still that corresponding to the addition of $12 \mathrm{mC}$ of Co to the deposit of $12 \mathrm{mC}$ of $\mathrm{Ag}$.

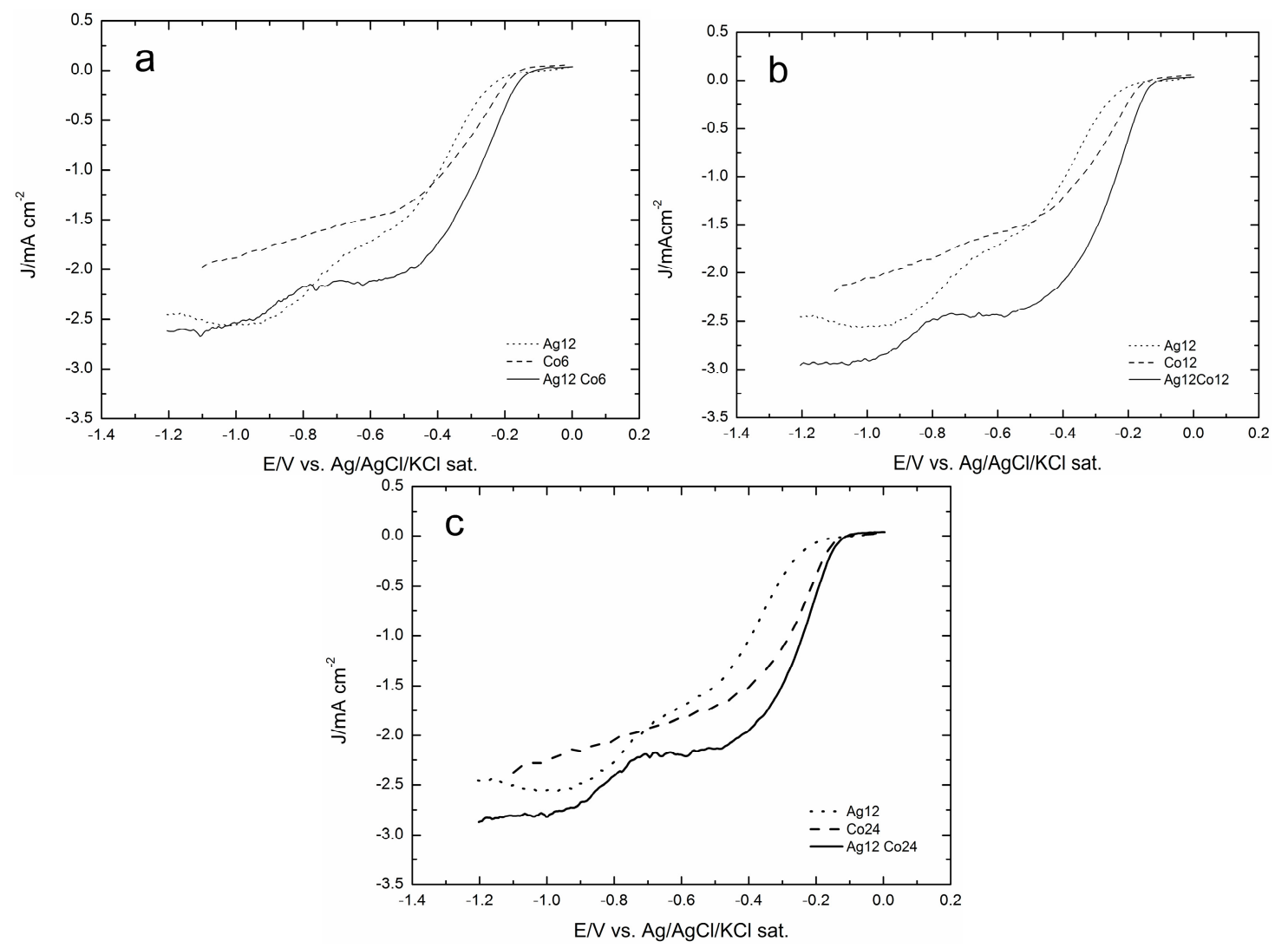

Figure 8. The oxygen reduction reaction (ORR) of the GC/Ag12Co samples and the corresponding $\mathrm{GC} / \mathrm{Co}$ samples with the same amount of cobalt of (a) $6 \mathrm{mC}$, (b) $12 \mathrm{mC}$ and (c) $24 \mathrm{mC}$ are compared with the curve of the GC/Ag12 sample of [31]. All curves are recorded at $500 \mathrm{rpm}$ with a scan rate of $50 \mathrm{mV} \cdot \mathrm{s}^{-1}$.

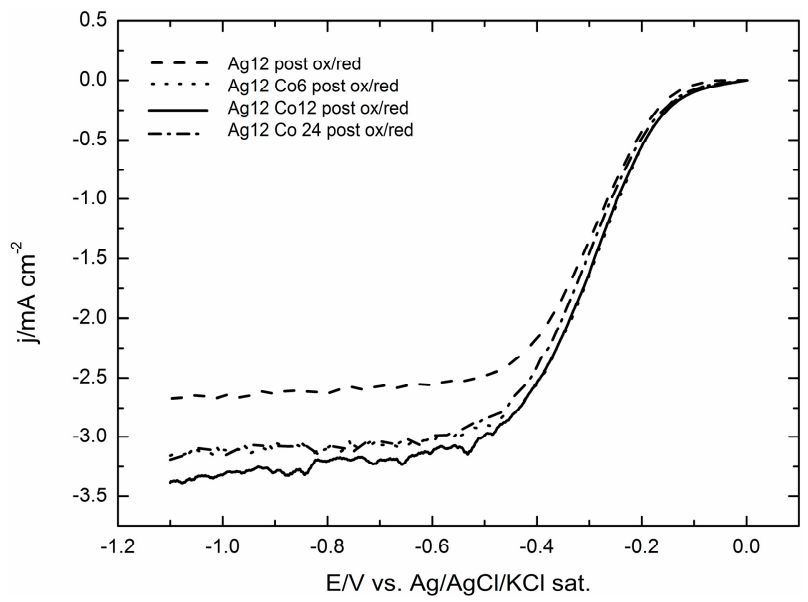

Figure 9. The effect of the oxidative/reductive treatment on the ORR of the GC/Ag of [31] and $\mathrm{GC} / \mathrm{AgCo}$ samples recorded at $500 \mathrm{rpm}$ and with a scan rate of $50 \mathrm{mV} \cdot \mathrm{s}^{-1}$. 
For a more detailed analysis, Figure 10 stresses the strong enhancement imparted by the pretreatment protocol, both on the deposits of silver alone and on the deposits also containing cobalt.

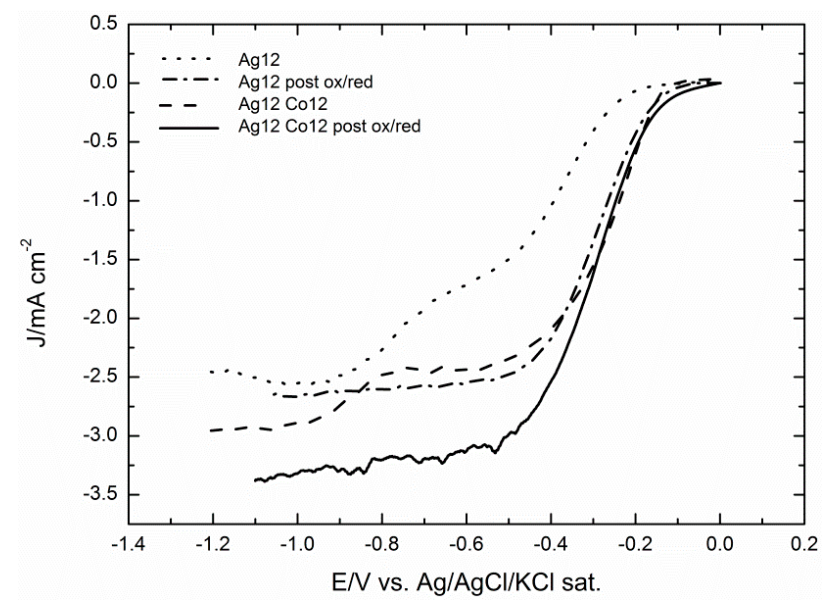

Figure 10. ORR of the best performing catalyst made by GC/Ag12Co12 before and after the oxidative/reductive treatment recorded at $500 \mathrm{rpm}$ and with a scan rate of $50 \mathrm{mV} \cdot \mathrm{s}^{-1}$. The curves are compared to the GC/Ag samples of [31].

Tafel plots reported in Figure 11 show that the shape of the activated curve of the $\mathrm{Ag} / \mathrm{Co}$ deposit (solid curve) is similar to that of the activated Ag (dotted curve), thus denoting that the same reaction mechanism is operating.

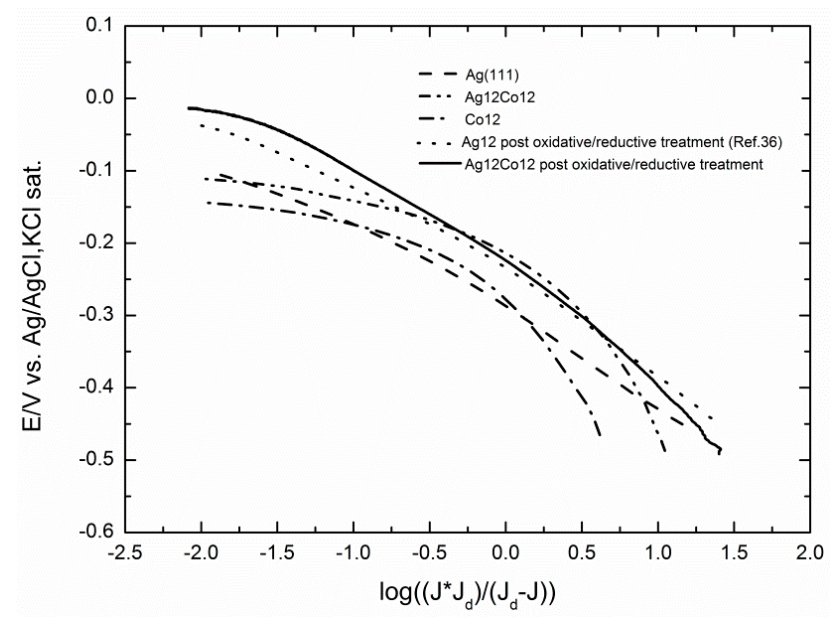

Figure 11. The Tafel plots for the ORR of the GC/Co, GC/Ag12Co12 before and after the oxidative/reductive treatment are compared to the Tafel plot of GC/Ag12 sample reported in [31] and the Tafel plot of a $\operatorname{Ag}(111)$ electrode.

Both curves are linear over large potential intervals and exhibit slopes very close to that of $\operatorname{Ag}(111)$ (dashed curve) [8,31]. It is worthwhile to note that the Tafel plot of the not pre-treated $\mathrm{Ag} / \mathrm{Co}$ sample appears to be a continuous curve for which it is impossible to determine a single slope value. This shape is similar to that of a deposit of Co alone, with the only advantage of a positive shift of the reduction potential already observed in Figure 8a-c. As already reported in [28], such a different shape of the Tafel plots should rule out that the enhanced catalytic effect could be solely ascribed to a mere increase of the 
electrode area as a consequence of the surface roughening during the pretreatment and that it should be better ascribed to the formation of oxydril-containing species.

The number of electrons transferred per $\mathrm{O}_{2}$ molecule can be estimated using either the Levich or the Koutecky-Levich equation on ORR curves obtained at different rotation rates. More precisely, the Levich plot is used when the process is diffusion controlled by the very beginning of the reduction curve, whereas the Koutecky-Levich plot better accounts for the kinetic contributions that are responsible for the deviation of the curve from the characteristic sigmoidal shape.

As shown by Figure 9, the shape of ORR curves registered on the sample containing either Ag or $\mathrm{Ag} / \mathrm{Co}$, both of them undergoing the oxidation/reduction pretreatment, justifies the use of the Levich equation:

$$
\mathrm{j}_{\mathrm{d}}=0.620 \mathrm{n} \mathrm{F} \mathrm{D}_{\mathrm{O}}^{2 / 3} v^{-1 / 6} \mathrm{C}_{\mathrm{O}} \omega^{1 / 2}
$$

where $\mathrm{j}_{\mathrm{d}}$ is the diffusion limited current density, $\mathrm{n}$ is the number of exchanged electrons, $\mathrm{F}$ is the Faraday constant, $\mathrm{D}_{0}$ is the oxygen diffusion coefficient $\left(1.95 \times 10^{-5} \mathrm{~cm}^{2} / \mathrm{s}\right)$ [35], $\omega$ is the angular rotation rate of the electrode (in rad/s), $v$ is the kinematic viscosity of the solution $\left(0.008977 \mathrm{~cm}^{2} / \mathrm{s}\right.$ ) and $\mathrm{C}_{0}$ is the $\mathrm{O}_{2}$ solubility in solution $\left(1.15 \times 10^{-3} \mathrm{~mol} / \mathrm{dm}^{3}\right)$ [35]. Figure 12 shows that in the potential region between -0.8 and $-1.1 \mathrm{~V}$, the plots of $\mathrm{j}_{\mathrm{d}}$ against $\mathrm{f}^{1 / 2}$, where $\mathrm{f}$ is the angular rotation rate of the electrode in $\mathrm{rpm}$, are straight lines intersecting the origin and with slopes yielding $\mathrm{n}$ values ranging between 3.22 and 3.53 for the Ag sample and 3.8 and 4.03 for $\mathrm{Ag} / \mathrm{Co}$ (see the inset of Figure 12). This result justifies the increase in the cathodic current density of the Ag/Co sample observed in Figure 9 well.

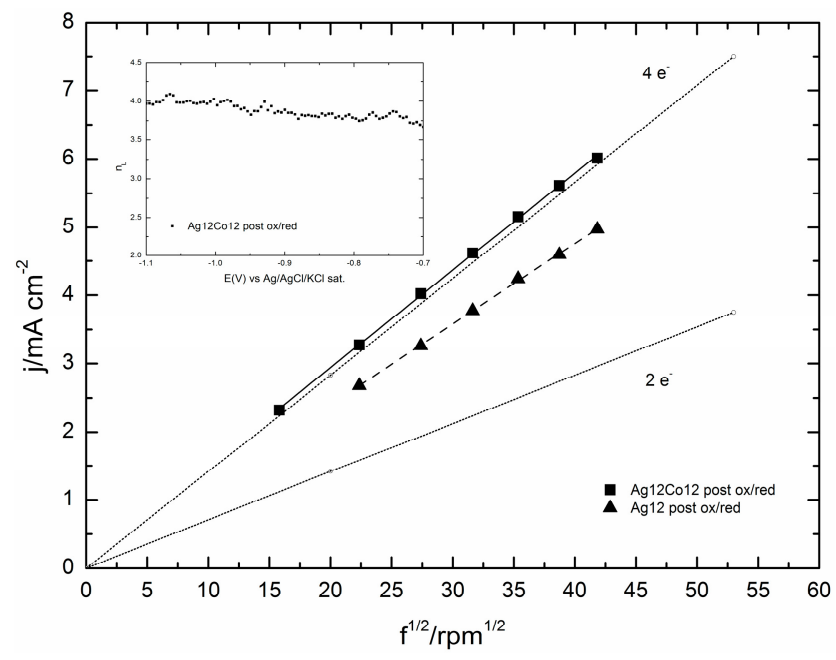

Figure 12. The Levich plot of the GC/Ag12Co12 after the oxidative/reductive treatment and the $\mathrm{GC} / \mathrm{Ag} 12$ sample after the same treatment at $\mathrm{E}=-1.1 \mathrm{~V}$ is reported. Inset: the average number of electrons exchanged during the ORR and extrapolated from the Levich plot of the $\mathrm{GC} / \mathrm{Ag} 12 \mathrm{Co} 12$ sample is reported in the potential range $-0.8--1.1 \mathrm{~V}$.

\subsection{Electrocatalytic Evaluation}

The catalytic activity of a catalyst may be verified by parameters, such as the electrochemically-active surface area (ECSA), specific activity and mass activity [40,41]. In our case, the analysis was carried out on the silver microparticles of Figure 9 at the potential $\mathrm{E}_{1 / 2}=-0.29 \mathrm{~V}$ (equal 
to $0.68 \mathrm{~V}$ versus the reference hydrogen electrode (RHE)), re-examining the experimental data of [31]. There, the real area had been determined by depositing $\mathrm{Pb}$ at underpotential and measuring the charge involved in its re-dissolution. Thus, a real area of $1.75 \mathrm{~cm}^{2}$ was found for a deposit of $12 \mathrm{mC}$ of silver on a $0.785-\mathrm{cm}^{2} \mathrm{GC}$ electrode, corresponding to a silver loading of $13.4 \mu \mathrm{g}$. Once corrected for the roughness factor, the silver loading yields an ECSA value equal to $13 \mathrm{~m}^{2} \cdot \mathrm{g}^{-1}$.

Then, the kinetic current measured at $-0.29 \mathrm{~V}, \mathrm{I}=1 \mathrm{~mA}$, was divided either by the silver loading or by the real area to get the mass activity, MA, or the specific activity, SA.

As shown in Table 2, our values for ECSA, SA and MA are of the same magnitude order of those reported in [41] for Pt/Vulcan catalysts. Of course, as expected, the whole ORR curve on silver is shifted towards more negative potentials.

Table 2. Kinetic parameters of a commercial Pt/Vulcan catalyst and the Ag 12 post ox/red sample: electrochemical surface area (ECSA) half wave potential ( $\left.\mathrm{E}_{1 / 2}\right)$, specific activity $(\mathrm{SAE} 1 / 2)$ and mass activity $(\mathrm{MAE} 1 / 2)$.

\begin{tabular}{ccccc}
\hline Samples & ECSA $\left(\mathbf{m}^{\mathbf{2}} \cdot \mathbf{g}^{-\mathbf{1}}\right)$ & $\mathbf{E}_{\mathbf{1 / 2}}(\mathbf{m V}) \boldsymbol{v s} . \mathbf{R H E}$ & $\mathbf{S A}_{\mathrm{E} 1 / 2}\left(\mathbf{m A} \cdot \mathbf{c m}^{-\mathbf{2}}\right)$ & $\mathbf{M A}_{\mathrm{E} 1 / 2}\left(\mathbf{A}^{\cdot} \cdot \mathbf{g}^{-\mathbf{1}}\right)$ \\
\hline Pt/Vulcan [42] & 44 & 854 & 0.21 & 92 \\
Ag 12 post ox/red & 13 & 680 & 0.57 & 75 \\
\hline
\end{tabular}

The addition of cobalt strongly enhances the limiting current due to the significant increase in the number of electron, thus supporting the hypothesis of a synergic effect on silver.

\section{Experimental Section}

Merck analytical reagent-grade $\mathrm{AgNO}_{3}, \mathrm{CoSO}_{4}, \mathrm{Na}_{2} \mathrm{~S}_{2} \mathrm{O}_{3}$ and $\mathrm{KOH}$ were used without further purification. Merk Suprapur $\mathrm{HClO}_{4}$ and Aldrich $\mathrm{NH}_{4} \mathrm{OH}$ were used to prepare the $\mathrm{pH} 9.2$ ammonia buffer used as the supporting electrolyte. The solutions were freshly prepared just before the beginning of each series of measurements. An automated deposition apparatus consisting of Pyrex solutions reservoirs, solenoid valves, a distribution valve and a flow-cell was used under the control of a computer. The working electrode was SIGRADUR ${ }^{\circledR}$ G Glassy Carbon from the HTW Hochtemperatur-Werkstoffe GmbH Company (Thierhaupten, Germany). The electrolytic cell used for the electrodeposition study was a Kel-F cylinder with a 10-mm inner diameter, delimited by the working electrode (a disk of $15 \mathrm{~mm}$ in diameter) on one side and the counter electrode on the other side. The resulting geometric area of the electrode is $0.785 \mathrm{~cm}^{2}$. The inlet and the outlet for the solutions were placed on the sidewalls of the cylinder. The counter electrode was a gold foil, and the reference electrode was an $\mathrm{Ag} / \mathrm{AgCl} / \mathrm{KCl}$ saturated electrode placed on the outlet tubing. Both the distribution valve and the cell had been designed and realized in the workshop of our department [42]. The solution is pushed into the cell by applying a pressure as low as $0.3 \mathrm{~atm}$ that determines a flow-rate of about $1 \mathrm{~mL} \cdot \mathrm{s}^{-1}$. After filling the cell, the pressure is no longer applied, so that the flow stopped during deposition. Simple homemade software allows for filling the cell with the various solutions and controls the deposition by keeping the potential at the planned value for the time necessary to deposit the programmed amount of silver.

Before silver and cobalt depositions, the working electrode was mechanically polished with alumina powders of decreasing size down to $1 \mu \mathrm{m}$. After each step of the abrasion procedure, the electrode was washed with bidistilled water. If already used in preceding measurements, the electrode was treated with 
an additional step of chemical etching based on a mixture of $\mathrm{H}_{2} \mathrm{O}_{2}$ and $\mathrm{NH}_{3}$ that ensured the dissolution of any remaining traces of silver. An electrochemical activation of the GC surface was made inside the electrolytic cell by alternating the application of potentials as negative as $-1.6 \mathrm{~V}$ and as positive as $+1.5 \mathrm{~V}$, keeping the electrode at the selected potential for $60 \mathrm{~s}$ while rinsing the cell with ammonia buffer every $30 \mathrm{~s}$. The electrode surface final check, carried out recording a cyclic voltammogram in ammonia buffer, showed a flat double layer region between +0.8 and $-1.2 \mathrm{~V}$, approximately.

After each silver and/or cobalt deposition, the electrode was transferred to the electrolytic cell used for the Rotating Disk Electrode (RDE) catalytic measurement that was a Metrohm glass cell equipped with 4 glass ports (Herisau, Switzerland). The working GC-modified electrode placed on a Teflon support realized in the workshop of our department was connected to an AutoLAB RDE-2 support rotating electrode managed by an AutoLAB manual motor controller. $\mathrm{An} \mathrm{Ag} / \mathrm{AgCl} / \mathrm{KCl}$ saturated) reference electrode and a Pt wire counter electrode were used. A glass bubbler connected to an $\mathrm{O}_{2}$ bottle was used to saturate the $\mathrm{KOH} 0.1 \mathrm{M}$ electrolyte solution.

\section{Conclusions}

The behaviour of cobalt deposition was investigated both on GC and on microparticles of silver obtained depositing $12 \mathrm{mC}$ of silver on a $0.785-\mathrm{cm}^{2} \mathrm{GC}$ electrode. Aiming at depositing very small amounts of either silver and/or cobalt, we used a purpose-developed program that allowed for strictly controlling the amount of deposition, resulting in a good reproducibility of all reported experiments.

The polarization curves recorded on a rotating-disc working electrode for the ORR on increasing deposits of cobalt on GC show that the onset potential progressively shifts towards less negative potentials up to a deposit equal to $18 \mathrm{mC}$ (equal to $7.0 \mu \mathrm{g} \mathrm{cm}^{-2}$ ), and then, it progressively shifts back to the negative potentials for the largest Co deposits. At the same time, the limited cathodic currents follow a similar behaviour. This is well depicted by both the plots of the potentials at which the curves reach the value of $0.5 \mathrm{~mA} \mathrm{~cm}^{-2}$ and the plots of the currents recorded at a potential $\mathrm{E}=-1.0 \mathrm{~V}$. The results are volcano curves that are typical of a mechanism where the adsorbed step is the rate-determining one. At the same time, the cyclic voltammograms recorded at different scan rates, v, at the $\mathrm{GC} / \mathrm{Co}(\mathrm{OH})_{2}$ electrode allow one to verify that $\mathrm{i}_{\mathrm{p}} / \mathrm{v}$ decreases with $\mathrm{v}$, thus confirming the autocatalytic mechanism imparted by the presence of cobalt as reported in [35]. Tafel plots of all Co deposits are continuous curves for which it is impossible to determine a single slope value (see Figure 11 for the Co deposit of $12 \mathrm{mC}$ ).

Amounts of Co corresponding to 6,12 and $24 \mathrm{mC}$ were added to the silver deposit of $12 \mathrm{mC}$ (corresponding to $17 \mu \mathrm{g} \cdot \mathrm{cm}^{-2}$ ) that had given the best catalytic effect in [31]. In all cases, the addition of Co enhances the catalytic effect of silver alone on ORR even with respect to $\operatorname{Ag}(111)$ (Figure 7). The comparison with the corresponding ORR curves of Co alone shows that the various ORRs of $\mathrm{Ag} / \mathrm{Co}$ not only seem to combine the behaviours of $\mathrm{Ag}$ and $\mathrm{Co}$ alone, but also result in final synergic enhancements. Thus, all Ag/Co ORRs are anticipated, probably because at the very beginning the contribution of the autocatalytic mechanism of Co prevails, but going on towards the negative values, the curves feel the higher catalytic effect of silver and, finally, reach a higher limiting cathodic current, thus indicating a higher number of electrons involved. However, Figure 11 shows that the Tafel plot of $\mathrm{Ag} / \mathrm{Co}$ maintains the curved shape of Co alone. 
A further enhancement of the catalytic effect is obtained when the $\mathrm{Ag} / \mathrm{Co}$ deposits undergo the activation protocol based on pretreatment oxidation/reduction cycles, as those described in [31] for the microparticles of silver alone. Together with the immediate observation of more regular shapes of the ORR curves with higher limiting cathodic currents (Figure 9), the Tafel plots of the pre-treated Ag/Co deposit are linear over large potential intervals and exhibit slopes very close to that of the pre-treated $\mathrm{Ag}$ alone and of $\operatorname{Ag}(111)$. This circumstance indicates that the same reaction mechanism is operating, even though the higher limiting cathodic currents suggest a higher number of electrons involved, as confirmed by the Levich analysis.

The electrochemical investigation is able to give detailed indication of the catalytic effect. However, we hope that the morphological and structural characterization that is now in progress will be able to explain how the synergy works [43].

\section{Acknowledgments}

The authors are grateful to Ferdinando Capolupo (Department of Chemistry, University of Florence for his technical assistance.

\section{Author Contributions}

Claudio Zafferoni: electrochemical synthesis, processing and writing contribution; Giacomo Cioncoloni: electrochemical synthesis; Maria Luisa Foresti: scientific and processing support; Luigi Dei, Emiliano Carretti, Francesco Vizza and Alessandro Lavacchi: scientific support; Massimo Innocenti: scientific and writing support.

\section{Conflicts of Interest}

The authors declare no conflict of interest.

\section{References and Notes}

1. Coutenceau, C.; Demarconnay, L.; Lamy, C.; Léger, J.-M. Development of electrocatalyst for solid alkaline fuel cell (SAFC). J. Power Sources 2006, 156, 14-19.

2. Zwetanova, A.; Juttner, K. The electrocatalytical influence of underpotential lead and thallium adsorbates on the cathodic reduction of oxygen on (111), (100) and (110) silver single-crystal surfaces. J. Electroanal. Chem. 1981, 119, 149-164.

3. McIntyre, J.D.E.; Peck, W.F. Electrochemistry at Single-Crystal Metal Electrodes. Electrocatalytic Effects on Surface Atomic Structure, Defects and Adatoms on Oxygen Reduction; The Electrochemical Society: Pennington, NJ, USA, 1984, pp. 102-130.

4. Wiberg, G.K.H.; Mayrhofer, K.J.J.; Arenz, M. Investigation of the Oxygen Reduction Activity on Silver-A Rotating Disc Electrode Study. Fuel Cells 2010, 10, 575-581.

5. Hurlen, T.; Sandler, Y.L.; Pantier, E.A. Reactions of oxygen and hydrogen peroxide at silver electrodes in alkaline solutions. Electrochim. Acta 1966, 11, 1463-1473.

6. Wachs, I.E.; Madix, R.J. The oxidation of methanol on a silver (110) catalyst. Surf. Sci. 1978, 76, 531-558. 
7. Blizanac, B.B.; Ross, P.N.; Markovic, N.M. Oxygen Reduction on Silver Low-Index Single-Crystal Surfaces in Alkaline Solution: Rotating Ring Diskag(hkl) Studies. J. Phys. Chem. B 2006, 110, 4735-4741.

8. Markovic, N.M.; Ross, P.N. Surface science studies of model fuel cell electrocatalysts. Surf. Sci. Rep. 2002, 45, 117-230.

9. Blizanac, B.B.; Lucas, C.; Gallagher, M.; Arenz, M.; Ross, P.N.; Markovic, N.M. Anion Adsorption, CO Oxidation, and Oxygen Reduction Reaction on a $\mathrm{Au}(100)$ Surface: The $\mathrm{pH}$ Effect. J. Phys. Chem. 2003, 108, 625-634.

10. Adzic, R.R. Recent Advanced in the Kinetics of Oxygen Reduction, Electrocatalysis; Wiley-VCH: New York, NY, USA, 1998; pp. 197-242.

11. Schmidt, T.J.; Stamenkovic, V.; Ross, P.N.; Markovic, N.M. Temperature dependent surface electrochemistry on Pt single crystals in alkaline electrolyte Part 3. The oxygen reduction reaction Phys. Chem. Chem. Phys. 2003, 5, 400-406.

12. Blizanac, B.B.; Ross, P.N.; Markovic, N.M. Oxygen electroreduction on $\operatorname{Ag}(111)$ : The pH effect, Electrochim. Acta 2007, 52, 2264-2271.

13. Ge, X.; Sumboja, A.; Wuu, D.; An, T.; Li, B.; Goh, F.W.T.; Hor, T.S.A.; Zong, Y.; Liu, Z. Oxygen Reduction in Alkaline Media: From Mechanisms to Recent Advances of Catalysts. ACS Catal. 2015, 5, 4643-4667.

14. Hansen, H.A.; Rossmeisl, J.; Nørskov, J.K. Surface Pourbaix diagrams and oxygen reduction activity of Pt, Ag and Ni(111) surfaces studied by DFT. Phys. Chem. Chem. Phys. 2008, 10, 3722-3730.

15. Fernandez, J.L.; Walsh, D.A.; Bard, A.J. Thermodynamic Guidelines for the Design of Bimetallic Catalysts for Oxygen Electroreduction and Rapid Screening by Scanning Electrochemical Microscopy. M-Co (M: Pd, Ag, Au). J. Am. Chem. Soc. 2005, 127, 357-365.

16. Wang, Y.; Balbuena, P.B. Design of Oxygen Reduction Bimetallic Catalysts: Ab-Initio-Derived Thermodynamic Guidelines. J. Phys. Chem. B 2005, 109, 18902-18906.

17. Lima, F.H.B.; de Castro, J.F.R.; Edson, A. Ticianelli, Silver-cobalt bimetallic particles for oxygen reduction in alkaline media. J. Power Sources 2006, 161, 806-812.

18. Loglio, F.; Lastraioli, E.; Bianchini, C.; Fontanesi, C.; Innocenti, M.; Lavacchi, A.; Vizza, F.; Foresti, M.L. Cobalt monolayer islands on $\mathrm{Ag}(111)$ for ORR catalysis. ChemSusChem 2011, 4, $1112-1117$.

19. Innocenti, M.; Bellandi, S.; Lastraioli, E.; Loglio, F.; Foresti, M.L. Selective Electrodesorption Based Atomic Layer Deposition (SEBALD): A novel electrochemical route to deposit metal clusters on Ag(111). Langmuir 2011, 27, 11704-11709.

20. Innocenti, M.; Zangari, G.; Zafferoni, C.; Bencistà, I.; Becucci, L.; Lavacchi, A.; di Benedetto, F.; Bellandi, S.; Vizza, F.; Foresti, M.L. Selective Electrodesorption Based Atomic Layer Deposition (SEBALD) modifications of silver surfaces for enhancing Oxygen ReductionReaction activity. J. Power Sources 2013, 241, 80-86.

21. Maheswari, S.; Sridhar, S.; Pitchumani, S. Carbon-Supported Silver as Cathode Electrocatalyst for Alkaline Polymer Electrolyte Membrane Fuel Cells. Electrocatal 2012, 3, 13-21. 
22. Demarconnay, L.; Coutanceau, C.; Léger, J.-M. Electroreduction of dioxygen (ORR) in alkaline medium on $\mathrm{Ag} / \mathrm{C}$ and $\mathrm{Pt} / \mathrm{C}$ nanostructured catalysts - effect of the presence of methanol. Electrochim. Acta 2004, 49, 4513-4521.

23. Lee, H.-K.; Shim, J.-P.; Shim, M.-J.; Kim, S.W.; Lee, J.-S. Mater, Oxygen reduction behavior with silver alloy catalyst in alkaline media. Chem. Phys. 1996, 45, 238-242.

24. Poon, K.C.; Tan, D.C.L.; Vo, T.D.T.; Khezri, B.; Su, H.; Webster, R.D.; Sato, H. Newly Developed Stepwise Electroless Deposition Enables a Remarkably Facile Synthesis of Highly Active and Stable Amorphous Pd Nanoparticle Electrocatalysts for Oxygen Reduction Reaction. J. Am. Chem. Soc. 2014, 136, 5217-5220.

25. Govindhan, M.; Chen, A. Simultaneous synthesis of gold nanoparticle/graphene nanocomposite for enhanced oxygen reduction reaction. J. Power Sources 2015, 274, 928-936.

26. Meille, V. Review on methods to deposit catalysts on structured surfaces. Appl. Catal. A 2006, 315, 1-17.

27. Gómez, E.; García-Torres, J.; Vallés, E. Electrodeposition of silver as a precursor matrix of magnetoresistive materials. Mater. Lett. 2007, 61, 1671-1674.

28. Garcia-Torres, J.; Gómez, E.; Vallés, E. Modification of magnetic and structural properties of Co and Co-Ag electrodeposits by sulphur incorporation. Mater. Chem. Phys. 2010, 122, 463-469.

29. Dimitrov, A.T.; Jordanov, S.H.; Popov, K.I.; Pavlovic, M.G.; Radmilovic, V. Electrodeposition of Ag from nitrate solutions: Part I. Effect of phosphate ions on morphology. J. Appl. Electrochem. 1998, 28, 791-796.

30. Zaman, H.; Yamada, A.; Filuda, H.; Ueda, Y. Magnetoresistance Effect in Co-Ag and Co-Cu Alloy Films Prepared by Electrodeposition. J. Electrochem. Soc. 1998, 145, 565-568.

31. Innocenti, M.; Zafferoni, C.; Lavacchi, A.; Becucci, L.; Di Benedetto, F.; Carretti, E.; Vizza, F.; Foresti, M.L. Electroactivation of Microparticles of Silver on Glassy Carbon for Oxygen Reduction and Oxidation Reactions. J. Electrochem. Soc. 2014, 161, D1-D7.

32. Matsushima, J.T.; Trivinho-Strixino, F.; Pereira, E.C. Investigation of cobalt deposition using the electrochemical quartz crystal microbalance. Electrochim. Acta 2006, 51, 1960-1966.

33. Grden, M.; Jagiello, J. Oxidation of electrodeposited cobalt electrodes in an alkaline electrolyte. J. Solid State Electrochem. 2013, 17, 145-156.

34. Erts, D.; Ahlberg, E.; Asbjörsson, J.; Olin, H.; Prikulis, J. Studies of the initial oxidation of cobalt in alkali solution using scanning electrochemical and atomic force microscopy. Appl. Phys. A 1998, 66, S477-S480.

35. Wang, Y.; Zhang, D.; Liu, H. A study of the catalysis of cobalt hydroxide towards the oxygen reduction in alkaline media. J. Power Sources 2010, 195, 3135-3139.

36. Ohsaka, T.; Mao, L.; Arihara, K.; Sotomura, T. Bifunctional Catalytic Activity of Manganese Oxide toward O2 Reduction-Novel Insight into the Mechanism of Alkaline Air Electrode. Electrochem. Commun. 2004, 6, 273-277.

37. Wu, J.; Zhang, D.; Wang, Y.; Wan, Y.; Hou, B. Catalytic activity of graphene-cobalt hydroxide composite for oxygen reduction reaction in alkaline media. J. Power Sources 2012, 198, 122-126.

38. Soto, A.B.; Arce, E.M.; Palomar-Pardavé, M.; Gonzalez, I. Electrochemical nucleation of cobalt onto glassy carbon electrode from ammonium chloride solutions. Electrochim. Acta 1996, 41, 2647-2655. 
39. Fletcher, S. Some new formulae applicable to electrochemical nucleation/growth collision. Electrochim. Acta 1983, 28, 917-923.

40. Mayrhofer, K.J.J.; Strmcnik, D.; Blizanac, B.B.; Stamenkovic, V.; Arenz, M.; Markovic, N.M. Measurement of oxygen reduction activities via the rotatingdisc electrode method: From Pt model surfaces to carbon-supported high surface area catalysts. Electrochim. Acta 2008, 53, 3181-3188.

41. Alegre, C.; Stassi, A.; Modica, E.; Lo Vecchio, C.; Aricò, A.S.; Baglio, V. Invesytigation of the activity and stability of Pd-based catalysts towards the oxygen reduction (ORR) and evolution, reactions (OER) for iron-air batteries. RSC Adv. 2015, 5, 25424-25427.

42. Innocenti, M.; Pezzatini, G.; Forni, F.; Foresti, M.L. CdS and ZnS, deposition on $\operatorname{Ag}(111)$ by electrochemical atomic layer epitaxy. J. Electrochem. Soc. 2001, 148, C357-C362.

43. The crystalline nature of the catalyst before and after the oxidative/reductive treatment will be evaluated, as well as the morphological and composition characterization after a deeper study at the European Synchtrotron Radiation Facility of Grenoble with experiments that are scheduled at the end of 2015.

Sample Availability: Not available.

(C) 2015 by the authors; licensee MDPI, Basel, Switzerland. This article is an open access article distributed under the terms and conditions of the Creative Commons Attribution license (http://creativecommons.org/licenses/by/4.0/). 